\title{
MODELAGEM DE INTENÇÃO EMPREENDEDORA DE ESTUDANTES UNIVERSITÁRIOS USANDO EQUAÇÕES ESTRUTURAIS
}

\author{
MODELING UNIVERSITY STUDENTS' ENTREPRENEURIAL INTENTION BY USING STRUCTURAL \\ EQUATIONS
}

Sérgio Henrique de Oliveira Lima *

Aluno de Mestrado do Programa de Pós-Graduação em Administração e Controladoria - Universidade

Federal do Ceará

Fortaleza, CE, Brasil

E-mail: shlima05@gmail.com

Domenico Ceglia

Aluno de Mestrado do Programa de Pós-Graduação em Administração e Controladoria - Universidade

Federal do Ceará

Fortaleza, CE, Brasil

E-mail: ceglia@gmail.com

Sílvia Maria Dias Pedro Rebouças

Professora Adjunta do Departamento de Administração da Faculdade de Economia, Administração, Atuárias

e Contabilidade - Universidade Federal do Ceará

Fortaleza, CE, Brasil

E-mail: smdpedro@gmail.com

Aurora Amélia Castro Teixeira

Professora Associada da Faculdade de Economia do Porto - Universidade do Porto

Porto, Portugal

E-mail: ateixeira@fep.up.pt

\section{RESUMO}

A pesquisa tradicional sobre intenção empreendedora tem destacado determinantes de naturezas demográfica (idade, gênero), psicológica (propensão ao risco, necessidade de realização) e contextual (experiência profissional, normas subjetivas). Este estudo se vale alguns fatores já abordados no campo - e adota novos - visando a compreender a intenção empreendedora de estudantes universitários. Com base em uma amostra de 242 alunos de Administração e Economia da Universidade Federal do Ceará, e utilizando modelagem de equações estruturais, as três hipóteses sugeridas a partir da literatura visitada foram confirmadas, levando à validação de um modelo em que (i) a experiência e o conhecimento acerca do processo empreendedor, (ii) a percepção sobre o tema empreendedorismo e a influência da imagem do empreendedor, e (iii) o estímulo ao empreendedorismo promovido pelas instituições de ensino superior - respectivamente, hipóteses $\mathrm{H}_{1}, \mathrm{H}_{2}$ e $\mathrm{H}_{3}$ - são fatores que explicam e influenciam a formação da intenção empreendedora.

Palavras-chave: Empreendedorismo. Intenção empreendedora. Modelo. Equações estruturais. Análise fatorial.

Data de submissão: 5 de fevereiro de 2015.

\section{ABSTRACT}

Traditional research on entrepreneurial intention has highlighted determinants of demographic (age, gender), psychological (risk propensity, need for achievement) and contextual nature (work experience, subjective norms). This study makes use of some factors already discussed in the field - and adopts new ones - to understand the entrepreneurial intention of university students. Based on a sample of 242 students of Business and Economics from Federal University of Ceará, and using structural equation modeling, the three hypotheses suggested from the visited literature were confirmed, leading to the validation of a model in which (i) the experience and the knowledge of the entrepreneurial process, (ii) the perception on the entrepreneurship topic and the influence of the entrepreneur's image, and (iii) the stimulus to entrepreneurship promoted by higher education institutions - respectively, hypotheses $H_{1}$, $\mathrm{H}_{2}$ and $\mathrm{H}_{3}$ - are factors that explain and influence the formation of entrepreneurial intention.

Keywords: Entrepreneurship; Entrepreneurial intention; Model; Structural equation; Factor analysis.

Data de aprovação: 25 de setembro de 2015. 


\section{INTRODUÇÃO}

O empreendedorismo tem crescentemente obtido espaço na agenda dos governos, tanto em países de economias emergentes quanto em países desenvolvidos (GÜROL; ATSAN, 2006; TEIXEIRA; DAVEY, 2010). O tema também tem alcançado cada vez mais relevância no âmbito acadêmico, tanto pela sua contribuição social como indutor de crescimento econômico e dinamização das economias locais (SCHMIDT; BOHNENBERGER, 2009), como pela necessidade de investigações científicas sobre seus determinantes (DAVIDSSON, 1995; CARVALHO; GONZÁLEZ, 2006).

A melhoria dos indicadores de progresso econômico e social está diretamente relacionada à capacidade empreendedora e de inovação de produtos e processos das nações (PORTER, 1992), embora tal manifestação empreendedora possa se dar por diferentes razões (necessidade ou oportunidade), de acordo, por exemplo, com a renda média per capita (FONTENELE, 2010).

Considerando que é da atividade empreendedora que emanam os processos de inovação (SCHUMPETER, 1984), e que estes contribuem para o aumento da competitividade e da eficiência dos mercados (NICKEL; NICOLITSAS; DRYDEN, 1997), evidencia-se o crescimento da atenção despendida tanto pela academia quanto por instituições governamentais no sentido de investigar os fatores condicionantes do comportamento empreendedor, ou a formação da intenção empreendedora, tendo, nos estudantes universitários, importantes sujeitos de pesquisa (TEIXEIRA; DAVEY, 2010).

Portanto, vê-se uma oportunidade de investigar a intenção empreendedora de alunos ingressantes na educação superior. A metodologia aplicada neste estudo guia-se, como referência, pelo mesmo instrumento de coleta elaborado e aplicado em pesquisas realizadas junto às instituições de ensino superior portuguesas (TEIXEIRA; DAVEY, 2010) e de outros países na Europa (a exemplo de Alemanha e Reino Unido), África (como África do Sul e Quênia), Ásia (Emirados Árabes Unidos) e Oceania (Austrália) (TEIXEIRA, 2013).

Tais pesquisas aplicaram técnicas estatísticas de regressão e, a partir delas, propuseram modelos "estruturais" não empíricos - na forma frameworks propositivos - com o intuito de prover uma melhor compreensão e assimilação de suas proposições (CARVALHO; GONZÁLEZ, 2006; TEIXEIRA; DAVEY, 2010; TEIXEIRA, 2013). De acordo com a revisão de literatura realizada, o único estudo que utilizou modelagem de equações estruturais com sucesso foi o de Lüthje e Franke (2003), que propuseram um modelo baseado em variáveis como traços de personalidade e fatores contextuais. Isto revela a oportunidade para novos estudos aplicando tal técnica.

Após verificada plausível a adoção do mesmo instrumento para uso de outras técnicas como análises fatoriais, optou-se pela consecução da pesquisa, que teve como objetivo geral propor e avaliar um modelo de equações estruturais capaz de explicar a intenção empreendedora de estudantes universitários. Para este fim, a instituição de ensino superior escolhida foi a Universidade Federal do Ceará. Como objetivo específico, buscou-se abordar novas variáveis explicativas da intenção empreendedora, complementares àquelas já amplamente investigadas, como forma de contribuir com a pesquisa no campo do empreendedorismo, pelo que se atribui um grau de inovação ao estudo.

A pesquisa está organizada, além desta introdução, em outras cinco seções: na revisão de literatura, busca-se suporte teórico para a proposição de um modelo estrutural explicativo para a formação da intenção 
empreendedora de estudantes universitários. Na seção reservada à metodologia, são discutidas questões referentes ao instrumento de coleta, amostra, procedimentos do teste empírico e operacionalização da redução de fatores. A quarta seção é dedicada à análise dos resultados, em que se apresentam os modelos estruturais e avalia-se a qualidade do ajustamento dos mesmos. Finalmente, uma seção apresenta as considerações finais, a qual é seguida das referências bibliográficas em que foi baseado o trabalho.

\section{ESTUDO DA FORMAÇÃO DE INTENÇÃO EMPREENDEDORA}

Investigar a formação da intenção empreendedora é determinante para o entendimento do processo de empreendedorismo como um todo. Ela é a força direcionadora subjacente ao estabelecimento de um novo empreendimento ou de inovações de valor em empreendimentos já existentes (BIRD, 1992).

Os estudos e discussões acerca da intenção empreendedora têm ganhado maior relevância no âmbito acadêmico a partir das últimas décadas do Século XX, a exemplo dos trabalhos de Shapero e Sokol (1982), Krueger (1993), Davidsson (1995), Audet (2000), Carvalho e González (2006) e Teixeira e Davey (2010)

Muitos estudos relacionados à formação de intenção empreendedora buscam suporte no campo da psicologia do comportamento, recorrendo aos trabalhos de Ajzen e Fishbein (1970, 1980), que culminaram com a proposição de sua Teoria da Ação Racional; Ajzen e Madden (1986); Ajzen (1991) e sua Teoria do Comportamento Planejado; Shapero e Sokol (1982) e sua abordagem das dimensões sociais relacionadas à criação de um empreendimento.

Tentam responder à mesma questão: quais os fatores que levam um indivíduo a tomar a arriscada decisão de empreender? A observação informal cotidiana sugere que algumas pessoas têm maior propensão para empreender, em relação a outras que, em outro extremo, assumem posição de total restrição a esta ventura. Quais as razões subjacentes deste fenômeno? Essas questões denotam um crescente interesse na identificação dos fatores que levam um indivíduo a se tornar um empresário (MARTíNEZ; MORA; VILA, 2007).

Segundo Bird (1992), a intenção pode ser vista como um estado de espírito em que a atenção da pessoa está dirigida para uma determinada situação, com vista a alcançar uma meta. Pode-se considerar que a concretização da ideia de criar uma nova empresa é precedida pela intenção, a qual, por sua vez, pode ser planejada durante algum tempo. Entretanto, em alguns casos, a intenção é formada no momento antes de se concretizar a ideia, enquanto que, em outros, ela não coincide com o comportamento manifestado. Logo, a análise da intenção empreendedora pode ser assumida para prever o comportamento de um indivíduo pretenso a fundar uma empresa própria (DAVIDSSON, 1995).

Há estudos que buscam caracterizar traços de personalidade ou perfis psicológicos típicos de pessoas empreendedoras - a exemplo de Nicholson (1998) - embora estes não levem em consideração a formação da intenção, ou seja, o processo cognitivo que culminará com o comportamento de fundar uma empresa. Sagie e Elizur (1999) e Teixeira e Davey (2010) investigaram o papel da necessidade de realização, característica presente em indivíduos empreendedores.

Hyrsky e Tuunanen (1999), Douglas e Shepherd (2002) e Barbosa, Gerhardt e Kickul (2007) investigaram a propensão ao risco como fator determinante da ação empreendedora. Antecedendo estes autores, Das e Teng (1997) argumentam que a assunção de riscos é uma característica inerente ao 
comportamento empreendedor; acrescentam ainda que há um componente temporal presente no risco (longo ou curto prazo), o qual permite diferenciar entre empreendedores por oportunidade ou por necessidade.

Em complemento a esta vertente psicológica, Gatewood et al. (2002) debruçaram-se sobre o papel que a expectativa de performance, baseada na capacidade percebida, desempenha sobre as motivações que uma pessoa tem para perseverar em uma jornada empreendedora.

Sob esta mesma perspectiva, Wood, Williams e Grégoire (2012) propõem um framework que integra os processos cognitivos que promovem a ação empreendedora em cada uma das fases que a antecedem, a saber: pensamento empreendedor, identificação da oportunidade, avaliação da oportunidade e formação da intenção. Avaliam também como se dá a transição entre estas fases.

Este artigo pretende, então, estender a pesquisa no campo, apoiando-se em resultados já propostos. As características que serão investigadas como variáveis explicativas da intenção empreendedora são discutidas a seguir.

\section{A INFLUÊNCIA DO CONHECIMENTO E DA EXPERIÊNCIA PROFISSIONAL E EMPREENDEDORA}

Delmar e Davidsson (2000) realizaram estudos comparando a intenção empreendedora cross-cultural entre Suécia, Estados Unidos e Noruega. Identificaram que a experiências empreendedoras passadas são um importante explicador da decisão de empreender. De fato, esta aprendizagem dota os indivíduos de conhecimento prático acerca dos passos necessários para a implementação de seus negócios. Os autores evidenciaram ainda que a experiência profissional como empregado não tem impacto significativo sobre a intenção empreendedora, contrariando os resultados de Bosma, van Praag e de Wit (2000), que provaram que esta variável é decisiva para o sucesso de um empreendimento. Estes autores, por outro lado, corroboram os achados de Delmar e Davidsson (2000), ao evidenciarem a importância da vivência como empreendedor para obtenção de maiores lucros.

De Wit e van Winden (1991) incluem em seus testes empíricos as variáveis capacidade gerencial e desempenho como empregado, características que presumem a experiência prévia do sujeito da pesquisa. Teixeira e Davey (2010) igualmente confirmam empiricamente a relevância, entre outros fatores, da experiência profissional como um antecedente significativo da intenção empreendedora.

O conhecimento sobre cada etapa do processo de criação de uma empresa também influencia diretamente a formação da intenção empreendedora (VENESAAR; KALLASTE; KÜTTIM, 2014). Avaliando uma amostra de estudantes de alguns países europeus, os autores identificaram, em geral, avaliações bastante baixas para as declarações relacionadas ao processo de fundação da uma empresa, o que pode suscitar uma necessidade de promoção mais forte por parte das universidades.

Este aspecto é também investigado por Choi e Park (2015), para quem a contribuição da universidade para a formação dos jovens universitários nas etapas do processo de constituição de novas empresas é relevante. Neste sentido, sugerem os autores, as instituições acadêmicas devem se preocupar em desenvolver programas voltados à formação empreendedora, a fim de suprir a carência de conhecimento específico demonstrada pelos estudantes. 
Estas discussões levam a propor a seguinte hipótese:

$H_{1}$ : $O$ conhecimento e a experiência empreendedora influenciam positivamente a intenção empreendedora dos estudantes universitários.

É verossímil supor que experiência e conhecimento podem ter relação com a percepção dos estudantes acerca do fenômeno empreendedorismo. É o que se discute a seguir.

\section{A INFLUÊNCIA DA PERCEPÇÃO EMPREENDEDORA}

Muitos jovens, talvez em virtude do próprio estágio de vida em que se encontram, podem enxergar em grandes empreendedores uma fonte de inspiração que, eventualmente, leva-os a desejar seguir caminhos semelhantes, em detrimento da carreira tradicional como empregados de empresa privada ou mesmo na administração pública. A como os jovens enxergam a atividade empreendedora e a figura do empreendedor se nomeou aqui percepção empreendedora.

Abordando o empreendedorismo desde uma perspectiva estética, Riot (2013) sinaliza para a mística e a genialidade que podem estar por trás dos grandes empreendedores (seu estudo baseou-se em Coco Chanel), embora isso, por vezes, seja mal representado pela forma como suas histórias, imagens e biografias são propaladas. A despeito desta ressalva, é fato que alguns empreendedores se tornam "quase mitos" e influenciam gerações de jovens.

Há interessantes contribuições do campo da psicologia, como aquelas trazidas por Rock (1985), em seu estudo sobre a influência do conhecimento na formação das percepções. Neste caso, afirma o autor, o conhecimento armazenado, advindo de experiências passadas, governa o processo cognitivo e interpretativo de construção das percepções. Surgem então duas relevantes implicações para este artigo: a primeira sugere uma relação estreita entre a experiência e o conhecimento empreendedor e a formação das percepções acerca da figura do empreendedor; a segunda, e mais relevante para este tópico, diz respeito ao fato de que a percepção formada, em se tratando de construção de percepção empreendedora, pode impactar na intenção de empreender, que, segundo Bird (1988 apud Busenitz e Lau, 1996), surge da interação entre a forma de pensar de uma pessoa, as vivências históricas individuais, sua personalidade atual e o ambiente social e econômico.

Reynolds et al. (1999 apud Verheul et al. 2001) indicam que as histórias na mídia sobre empreendedores de sucesso, bem como o respeito em relação àqueles que iniciam um negócio podem também ser componentes influenciadores da cultura empreendedora, havendo uma correlação positiva entre respeito por empreendedores e a taxa de abertura de firmas.

Recentemente, alguns estudos passaram a avaliar a associação entre traços de personalidade narcisistas com aspectos comportamentais como propensão ao risco (FOSTER; SHENESEY; GOFF, 2009; FOSTER; MISRA; REIDY, 2009). Como a propensão à tomada de risco, aliada à necessidade de realização e à busca de sucesso são características típicas de empreendedores, esta percepção da figura do empreendedor poderia também influenciar a intenção empreendedora de estudantes universitários.

Mathieu e St-Jean (2013) avaliaram quatro grupos distintos - funcionários públicos, bancários, estudantes não empreendedores e estudantes empreendedores - por meio de uma escala de narcisismo, e 
constataram que (i) estudantes empreendedores são o grupo mais narcisista, e (ii) há forte correlação entre narcisismo e autoeficácia, locus de controle e propensão ao risco.

Esta percepção narcisista, em linha com a crença de que é capaz e com o entusiasmo natural da figura do empreendedor podem ajudar a moldar a intenção empreendedora dos estudantes, de onde se postula a segunda hipótese deste artigo:

$\mathrm{H}_{2}$ : A percepção empreendedora influencia positivamente a intenção empreendedora dos estudantes universitários.

Uma discussão importante tem dado ênfase ao papel da universidade. Seja como indutor indireto do empreendedorismo via qualificada formação de nível superior, seja por meio de uma educação voltada diretamente à formação empreendedora e sua influência na intenção de criação de novos negócios.

\section{A INFLUÊNCIA DOS ESTÍMULOS DAS INSTITUIÇÕES DE ENSINO SUPERIOR (IES'S)}

A influência da educação em seu sentido lato (nível de escolaridade ou grau de instrução) sobre a formação da intenção empreendedora já vem sendo bastante debatida (HISRICH, 1990; VERHUEL et al., 2001). Estudos como os de Davidsson (1995), van der Kuip (1998 apud Verhuel et al., 2001), Sánchez (2011) e García (2014) confirmam a hipótese de influencia positiva e significativa do grau de escolaridade (ou anos de ensino) sobre a intenção de empreender. O que se pretende aqui é investigar o papel da educação em seu sentido estrito, relacionado diretamente à formação para o empreendedorismo.

As universidades podem desempenhar um importante papel ao buscarem desenvolver as capacidades empreendedoras dos estudantes, oferecendo cursos que abordam o tema empreendedorismo e incluindo em seus programas e grades curriculares disciplinas correlatas. Discutem-se agora evidências empíricas que dão suporte a esta estratégia.

Paço et al. (2011) realizaram pesquisa com jovens pré-universitários e também constataram a relevância da formação e capacitação em empreendedorismo. Seus resultados geraram importantes implicações para a elaboração de programas educacionais voltados especificamente ao empreendedorismo, pois podem promover o surgimento de novos negócios, pela sua capacidade de impulsionar o espírito empreendedor dos jovens.

Van der Kuip (1998 apud Verhuel et al., 2001) argumenta que qualidades empreendedoras, como perseverança, criatividade e assunção de riscos podem ser aprimoradas por meio de projetos que envolvam estes aspectos tanto nas fases iniciais da educação (infantil) até a universidade.

Investigando o impacto da educação empreendedora sobre estudantes universitários espanhóis, Lanero et al. (2011) concluíram que esta exerce influência positiva e significativa sobre a percepção de viabilidade de um novo negócio. Tal percepção, por seu turno, afeta a intenção empreendedora, o que reforça a necessidade de um esforço conjunto de universidades, autoridades públicas e outros agentes afins na elaboração de estratégias integradas de educação empreendedora.

Liñán et al. (2011) reafirmam a necessidade de programas de educação voltados ao empreendedorismo, visto que elementos como viabilidade percebida e conveniência percebida foram empiricamente validados em seus estudos como principais determinantes da intenção empreendedora dos estudantes. Por isso, os programas de educação devem considerar estes elementos em sua formulação. 
Em uma pesquisa comparando dois grupos de estudantes, um que iria ingressar em um programa universitário de empreendedorismo e outro usado como grupo de controle, Sánchez (2011) identificou que houve incremento nas competências empreendedoras e na intenção de empreender dos estudantes do grupo que concluiu o programa, quando confrontando com resultados anteriores ao início do programa.

Segundo pesquisa de Canever et al. (2013), que investigaram estudantes de uma IES federal brasileira, as universidades poderiam criar cursos específicos para trabalhar junto aos seus alunos a aversão ao risco de empreender, estimulando contatos com casos locais e/ou regionais, o que permitiria elevar o nível de conhecimento das oportunidades de começar o seu próprio negócio. A existência de programas de educação voltados para o empreendedorismo entre os jovens estudantes de cursos de graduação é fundamental para a formação da intenção empreendedora entre estes sujeitos (CHOI; PARK, 2015), e pode atuar como estímulo para a assunção de riscos desta natureza.

A partir de dados de uma pesquisa survey internacional sobre intenção empreendedora de estudantes, Venesaar, Kallaste e Küttim (2014) compararam resultados de universitários da Estônia, Finlândia e Hungria entre si e com a média da Europa, e confirmaram a relevância dos estímulos proporcionados pelas instituições acadêmicas, como conhecimentos e habilidades empreendedoras. Os respondentes desta pesquisa, entretanto, não enxergavam uma "atmosfera" favorável ao empreendedorismo nas universidades em que estudavam.

Analisando dois grupos de estudantes universitários, sendo um submetido a formação específica em empreendedorismo e outro de controle, Rocha e Freitas (2014) constataram que aqueles que participaram de atividades educacionais de formação em empreendedorismo apresentaram maior pontuação em algumas escalas de competências empreendedoras quando comparados aos estudantes do grupo de controle, notadamente as competências relacionadas a planejamento, inovação, assunção de riscos e autorrealização.

Destas discussões, emerge a terceira hipótese deste artigo:

$H_{3}$ : $O$ estímulo da IES influencia positivamente a intenção empreendedora dos estudantes universitários.

O Quadro 1 reúne a abordagem teórica que deu suporte à pesquisa empírica. 
Quadro 1 - Suporte teórico para a pesquisa e hipóteses formuladas

\begin{tabular}{|c|c|c|c|}
\hline CONSTRUTOS & DESCRIÇÃO & AUTORES & HIPÓTESE \\
\hline $\begin{array}{l}\text { Conhecimento \& } \\
\text { Experiência }\end{array}$ & $\begin{array}{l}\text { Habilidade técnica como a } \\
\text { compreensão das etapas de } \\
\text { transformação de uma ideia em } \\
\text { negócio concreto. Busca de } \\
\text { informações afins, por meio de livros } \\
\text { e artigos, participação em } \\
\text { congressos e feiras. Conhecimento } \\
\text { sobre como e onde buscar } \\
\text { financiamento. Capacidade de } \\
\text { elaborar planos de negócio. }\end{array}$ & $\begin{array}{l}\text { de Wit \& van Winden } \\
\text { (1991); } \\
\text { Bosma, van Praag \& de Wit } \\
\text { (2000); } \\
\text { Delmar \& Davidsson } \\
\text { (2000); } \\
\text { Teixeira \& Davey (2010); } \\
\text { Venesaar, Kallaste \& } \\
\text { Küttim (2014); } \\
\text { Choi \& Park (2015). }\end{array}$ & $\begin{array}{l}\text { H}_{1} \text { : O conhecimento e a } \\
\text { experiência } \\
\text { empreendedora } \\
\text { influenciam positivamente a } \\
\text { intenção empreendedora } \\
\text { dos estudantes } \\
\text { universitários. }\end{array}$ \\
\hline $\begin{array}{l}\text { Percepção } \\
\text { Empreendedora }\end{array}$ & $\begin{array}{l}\text { Percepção dos estudantes em } \\
\text { relação ao tema empreendedorismo, } \\
\text { imagem que fazem da figura do } \\
\text { empreendedor. }\end{array}$ & $\begin{array}{l}\text { Rock (1985); } \\
\text { Bird (1988); } \\
\text { Reynolds et al. (1999); } \\
\text { Foster, Misra \& Reidy } \\
\text { (2009); } \\
\text { Foster, Shenesey \& Goff } \\
\text { (2009); } \\
\text { Mathieu \& St-Jean (2013); } \\
\text { Riot (2013); }\end{array}$ & $\begin{array}{l}\mathbf{H}_{2} \text { : A percepção } \\
\text { empreendedora influencia } \\
\text { positivamente a intenção } \\
\text { empreendedora dos } \\
\text { estudantes universitários. }\end{array}$ \\
\hline Estímulo IES & $\begin{array}{l}\text { Estímulos que a Instituição de Ensino } \\
\text { Superior proporciona por meio de } \\
\text { projetos de empreendedorismo, } \\
\text { eventos e conferências sobre o tema, } \\
\text { viabilização de redes de contato e } \\
\text { troca de experiências. }\end{array}$ & $\begin{array}{l}\text { van der Kuip (1998); } \\
\text { Paço et al. (2010); } \\
\text { Lanero et al. (2011); } \\
\text { Liñán et al. (2011); } \\
\text { Paço et al. (2011); } \\
\text { Sánchez (2011); } \\
\text { Canever et al. (2013); } \\
\text { García (2014); } \\
\text { Venesaar, Kallaste \& } \\
\text { Küttim (2014); } \\
\text { Rocha \& Freitas (2014); } \\
\text { Choi \& Park (2015). }\end{array}$ & $\begin{array}{l}\mathrm{H}_{3}: \text { O estímulo da IES } \\
\text { influencia positivamente a } \\
\text { intenção empreendedora } \\
\text { dos estudantes } \\
\text { universitários. }\end{array}$ \\
\hline
\end{tabular}

Fonte: Elaborado pelos autores.

\section{METODOLOGIA}

Considerando-se a classificação proposta por Collis e Hussey (2005), este estudo trata-se de uma pesquisa quantitativa, de natureza descritiva, pois visa a descrever características de determinada população ou fenômeno - a intenção empreendedora de alunos de instituições de ensino superior - e explicativa, por tentar estabelecer relações entre as variáveis, usando métodos padronizados de coleta e análise de dados.

A partir da revisão de literatura, o arcabouço teórico permitiu a proposição do primeiro modelo estrutural, valendo-se da técnica de Modelagem de Equações Estruturais (SEM - Structural Equations Modeling). Foram determinados o modelo de mensuração e o modelo estrutural, com as respectivas relações entre os construtos, representando as hipóteses a serem testadas. Para a realização de um teste empírico, adotou-se a estratégia de análise fatorial confirmatória (AFC), na qual, segundo Hair et al. (2009), o pesquisador está preocupado em confirmar a validade do modelo proposto para explicar o fenômeno sob investigação. A análise dos dados foi realizada por meio de programas computacionais de tratamento estatístico de dados: o SPSS - Statistical Package for Social Sciences (versão 21.0) e o AMOS - Analysis of MOment Structures (versão 20.0.0).

A despeito de se buscar propor um modelo que explique a intenção empreendedora dos estudantes universitários, não se pretende obter resultados generalizáveis, pois (i) sua amostra foi apanhada de forma intencional; e (ii) o resultado da aplicação da técnica de modelagem de equações estruturais somente pode 
propor um modelo que melhor se ajuste à realidade observada, não sendo possível eliminar a hipótese de existir(em) outro(s) modelo(s) explicativo(s) ainda mais bem ajustado(s) para tal fenômeno, a depender das variáveis e da teoria de base utilizada pelo pesquisador (HAIR et al., 2009).

\section{COLETA DE DADOS E AMOSTRA}

Para a coleta dos dados, foi replicado um questionário já validado em pesquisa sobre intenção empreendedora nas instituições de ensino superior de diversos países da Europa (a exemplo de Portugal, Alemanha e Reino Unido), África (como África do Sul e Quênia), Ásia (Emirados Árabes Unidos) e Oceania (Austrália) (TEIXEIRA; DAVEY, 2010; TEIXEIRA, 2013). O referido estudo de base teve por fim a proposição de um modelo de regressão logística capaz de descrever a propensão dos estudantes de Economia e Gestão ao empreendedorismo.

O presente artigo, como uma adaptação daquele à realidade específica do Estado do Ceará, buscou investigar a intenção empreendedora junto a estudantes do primeiro e segundo semestres letivos dos cursos de Administração e Ciências Econômicas da Universidade Federal do Ceará. A opção por estes dois cursos visou à maior aproximação possível à metodologia do estudo de base (TEIXEIRA, 2013), no que se refere à amostragem e coleta de dados. Estes cursos são considerados aqueles com maior incidência de estudos e práticas em empreendedorismo nas universidades europeias. Além disso, a tradição acadêmica na Europa não considera como graduações autônomas cursos correlatos como Ciências Contábeis, Finanças e Ciências Atuariais, o que ocorre no Brasil. De fato, seus equivalentes europeus são ofertados na forma de pósgraduação, ênfases ministradas logo que concluída a graduação nos cursos de Economia e Gestão. Estas razões justificam a escolha dos cursos de Administração e de Ciências Econômicas para a realização da pesquisa.

O instrumento de coleta consistiu basicamente de questões fechadas com respostas apontadas em escalas de Likert de cinco pontos. Como variáveis de controle foram utilizadas idade e gênero. O questionário foi aplicado de forma presencial em dois momentos distintos: (i) em fevereiro de 2013, com alunos de primeiro e segundo semestres letivos; e (ii) em novembro de 2013, com aqueles ingressantes no meio do ano, permitindo alcançar um total de 242 respondentes, adequando-se aos requisitos de tamanho de amostra para a metodologia.

Primeiramente, como recomendam Fávero et al. (2009), foi avaliada a qualidade básica da amostra, através de (i) rastreamento de respostas não engajadas, verificando o desvio-padrão entre as todas as respostas de cada respondente, o que não identificou nenhuma resposta viesadas; e (ii) rastreamento de missing data, o que levou à exclusão de seis questionários, por apresentarem número de respostas vazias superior a $10 \%$ do total de variáveis. Estes procedimentos produziram uma amostra final de 236 questionários válidos, número superior ao mínimo recomendado (150) para aplicação de modelagem de equações estruturais (HAIR et al., 2009) ou de 10 a 15 observações por cada variável manifesta (MARÔCO, 2010). Aplicou-se a substituição das respostas vazias restantes pela mediana de todas as suas observações. Tais verificações prévias são necessárias para melhor adequação da amostra, eliminando a possibilidade de vieses que enfraquecem a qualidade do modelo que se pretende propor. 
Após a realização de análise fatorial exploratória (para detalhes, ver Apêndice 1, e tabelas 1 a 4), chegou-se a uma estrutura fatorial composta por três construtos exógenos - Conhecimento \& Experiência, Estímulo IES e Percepção Empreendedora - explicando o construto dependente Intenção Empreendedora, e um total de quinze variáveis manifestas para todo modelo.

\section{MODELAGEM DE EQUAÇÕES ESTRUTURAIS}

A análise de equações estruturais é uma técnica que visa a testar a validade de modelos teóricos que definem relações hipotéticas de causalidade entre variáveis, ideal para aplicações em Ciências Sociais, pela natureza não diretamente observável das variáveis explicativas dos fenômenos, levando o pesquisador a deter-se a efeitos destas, os quais, por seu turno, são observáveis (MARÔCO, 2010).

Tais modelos podem ter a aptidão para explicar um dado fenômeno a partir da proposição de fatores (latentes) medidos em função de variáveis observáveis (manifestas), com uma capacidade desejável de explicação, e devem apresentar coeficientes de ajustamento, os quais têm por objetivos: (i) avaliar a extensão em que o modelo estimado consegue predizer a matriz de covariância real, observada; em última análise, pretendem aferir o grau de aderência entre a teoria de que se valeu o pesquisador e os dados reais da amostra (ajustamento absoluto); e (ii) medir a relação entre a qualidade do ajuste de um modelo e sua complexidade interna - ou o número de parâmetros estimados - sempre buscando comparar com a mesma relação de outro modelo concorrente ou alternativo (ajustamento parcimonioso) (HAIR et al. 2009). Neste estudo foram analisados os seguintes índices ${ }^{4}$ : para ajustamento absoluto: razão $X^{2} / g l$, SRMR, GFI, AGFI e RMSEA; para ajustamento incremental: CFI e NFI; e para ajustamento parcimonioso: PNFI, PCFI e PGFI.

Como já abordado, os estudos que apresentaram modelos ditos "estruturais" não propuseram, de fato, modelos empiricamente testados, mas somente frameworks que se limitavam a ilustrar a mensagem e/ou resultados obtidos por meio de outras técnicas, como regressão logística, regressão linear, entre outras.

Portanto, na tentativa de suplantar esta lacuna, serão apresentados nas próximas seções deste artigo os resultados do esforço despendido para a criação de um modelo que possa representar a intenção empreendedora dos estudantes da amostra em questão. Antes, uma breve análise descritiva será discutida, em função de variáveis demográficas como idade e gênero.

\section{ANÁLISE DOS RESULTADOS E DISCUSSÕES}

\section{Perfil da amostra}

Uma primeira análise foi realizada em função das variáveis demográficas consideradas no estudo. Observou-se que estudantes do sexo masculino representaram $57 \%$ da amostra. Em relação à idade, a média dos integrantes da amostra foi 22 anos; $73 \%$ deles possuem entre 16 e 22 anos, e quase $90 \%$ possuem até 27 anos. 


\section{Modelos de equações estruturais}

A partir da AFE abordada anteriormente, foram especificados e analisados dois modelos, que se distinguem entre si pela existência de correlações entre fatores latentes que são respaldadas na teoria. $O$ modelo 1 proposto não leva em consideração tais correlações, característica proposta nos modelos 2 e 3 . A seguir são apresentados os modelos e seus coeficientes padronizados estimados. A Figura 1 apresenta os coeficientes padronizados estimados pelo modelo 1 .

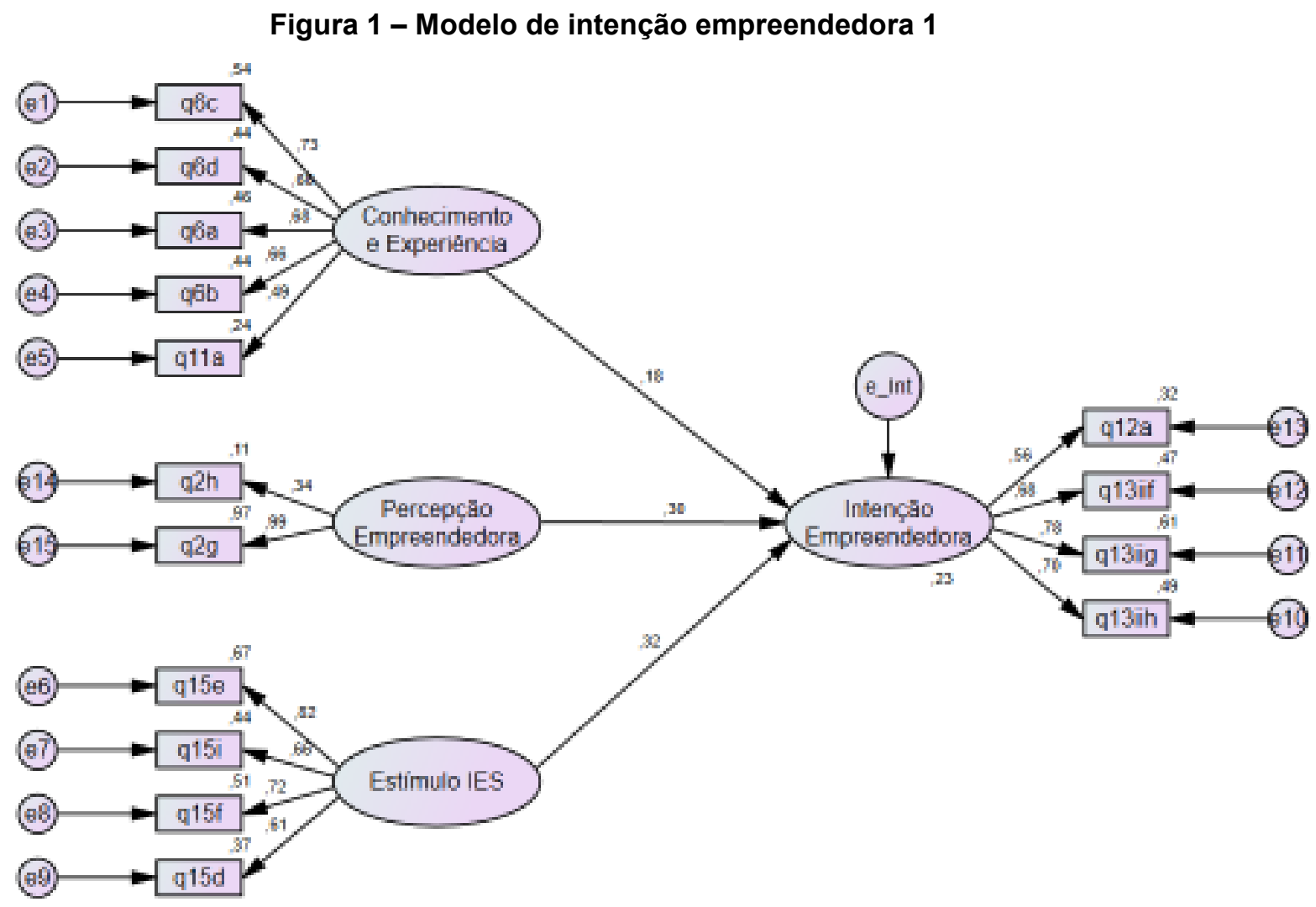

Fonte: Elaborado pelos autores.

O construto Estímulo IES (estímulo da Instituição de Ensino Superior) é o que possui maior impacto na Intenção Empreendedora (coeficiente de regressão padronizado de 0,324; $p$-value < 0,001). Em seguida, tem-se a Percepção Empreendedora $(0,296 ; p$-value < 0,001) e, por fim, o Conhecimento \& Experiência Empreendedora $(0,182 ; p$-value $=0,019)$. Em uma sentença, os três construtos apresentam influência significativa sobre a intenção empreendedora dos estudantes da amostra aos níveis de $1 \%, 1 \%$ e $5 \%$, respectivamente, confirmando as hipóteses $\mathrm{H}_{1}, \mathrm{H}_{2}$ e $\mathrm{H}_{3}$ sugeridas anteriormente.

Estes testes de significância são apresentados na Tabela 5, que mostra as estatísticas $p$-value dos modelos estrutural e de mensuração. 
Tabela 5 - Coeficientes de regressão do Modelo 1

\begin{tabular}{|c|c|c|c|c|c|}
\hline \multicolumn{4}{|c|}{ Relações } & Coeficiente & p-value ${ }^{a}$ \\
\hline \multirow{3}{*}{ Modelo Estrutural } & Int_Empreend & $\leftarrow$ & Conhec_Exp & 0,182 & 0,019 \\
\hline & Int_Empreend & $\leftarrow$ & Estimulo_IES & 0,324 & $* * *$ \\
\hline & Int_Empreend & $\leftarrow$ & Percep_Empreend & 0,296 & $* * *$ \\
\hline \multirow{15}{*}{$\begin{array}{c}\text { Modelo de } \\
\text { Mensuração }\end{array}$} & q6c & $\leftarrow$ & Conhec_Exp & 0,735 & $\mathrm{n} / \mathrm{a}$ \\
\hline & q6d & $\leftarrow$ & Conhec_Exp & 0,660 & $* * *$ \\
\hline & q6a & $\leftarrow$ & Conhec_Exp & 0,675 & $* * *$ \\
\hline & $q 6 b$ & $\leftarrow$ & Conhec_Exp & 0,660 & $* * *$ \\
\hline & q11a & $\leftarrow$ & Conhec_Exp & 0,485 & $* * *$ \\
\hline & q15e & $\leftarrow$ & Estimulo_IES & 0,820 & $\mathrm{n} / \mathrm{a}$ \\
\hline & q15i & $\leftarrow$ & Estimulo_IES & 0,664 & $* * *$ \\
\hline & $q 15 f$ & $\leftarrow$ & Estimulo_IES & 0,717 & $* * *$ \\
\hline & q15d & $\leftarrow$ & Estimulo_IES & 0,609 & $* * *$ \\
\hline & q2h & $\leftarrow$ & Percep_Empreend & 0,338 & $\mathrm{n} / \mathrm{a}$ \\
\hline & $q 2 g$ & $\leftarrow$ & Percep_Empreend & 0,987 & $0,128^{b}$ \\
\hline & q13iih & $\leftarrow$ & Int_Empreend & 0,698 & $\mathrm{n} / \mathrm{a}$ \\
\hline & q13iig & $\leftarrow$ & Int_Empreend & 0,783 & $* * *$ \\
\hline & q13iif & $\leftarrow$ & Int_Empreend & 0,683 & $* * *$ \\
\hline & q12a & $\leftarrow$ & Int_Empreend & 0,563 & $* * *$ \\
\hline
\end{tabular}

Fonte: Dados da pesquisa;

a quando "n/a", trata-se de coeficiente não padronizado de relações fixadas em "1" para o teste do modelo;

${ }^{\mathrm{b}}$ não significativo.

Em referência às variáveis manifestas, nota-se que todas as medidas foram significativas a $1 \%$ ( $p$ value $<0,001$ ), à exceção da variável "q2g" (não significativa; $p$-value $=0,128$ ), o que sugere sua retirada do modelo, ação que levaria à eliminação do construto Percepção Empreendedora do modelo proposto.

Embora as hipóteses tenham se confirmado, estas razões suscitam a proposição de um modelo alternativo. Modelos estruturais devem ser sempre vistos como uma das opções de explicação de um dado fenômeno, não necessariamente a melhor solução (HAIR et al. 2009). Destarte, os pesquisadores devem se preocupar em investigar se há outras melhores soluções possíveis, pelo que se justifica a análise de um segundo modelo.

No modelo 2, foram incluídas covariâncias entre os construtos latentes Conhecimento \& Experiência e Percepção Empreendedora (ROCK, 1985; RIOT, 2013), bem como entre Percepção Empreendedora e Estímulo IES (SÁNCHEZ, 2011).

Neste modelo, o construto Percepção Empreendedora assume a maior contribuição para a formação da Intenção Empreendedora (0,335; $p$-value = 0,001). Em seguida, tem-se o Estímulo IES $(0,295 ; p$-value < 0,001) e, por fim, como no modelo 1, o construto Conhecimento \& Experiência Empreendedora $(0,167 ; p$ value $=0,035)$. Sintetizando, também neste modelo os três construtos apresentam influência significativa sobre a intenção empreendedora dos estudantes da amostra aos níveis de 1\%, 1\% e 5\%, respectivamente, novamente confirmando as hipóteses sugeridas.

A Figura 2 apresenta o modelo reespecificado, conforme as características e coeficientes descritos. 
Figura 2 - Modelo de intenção empreendedora 2

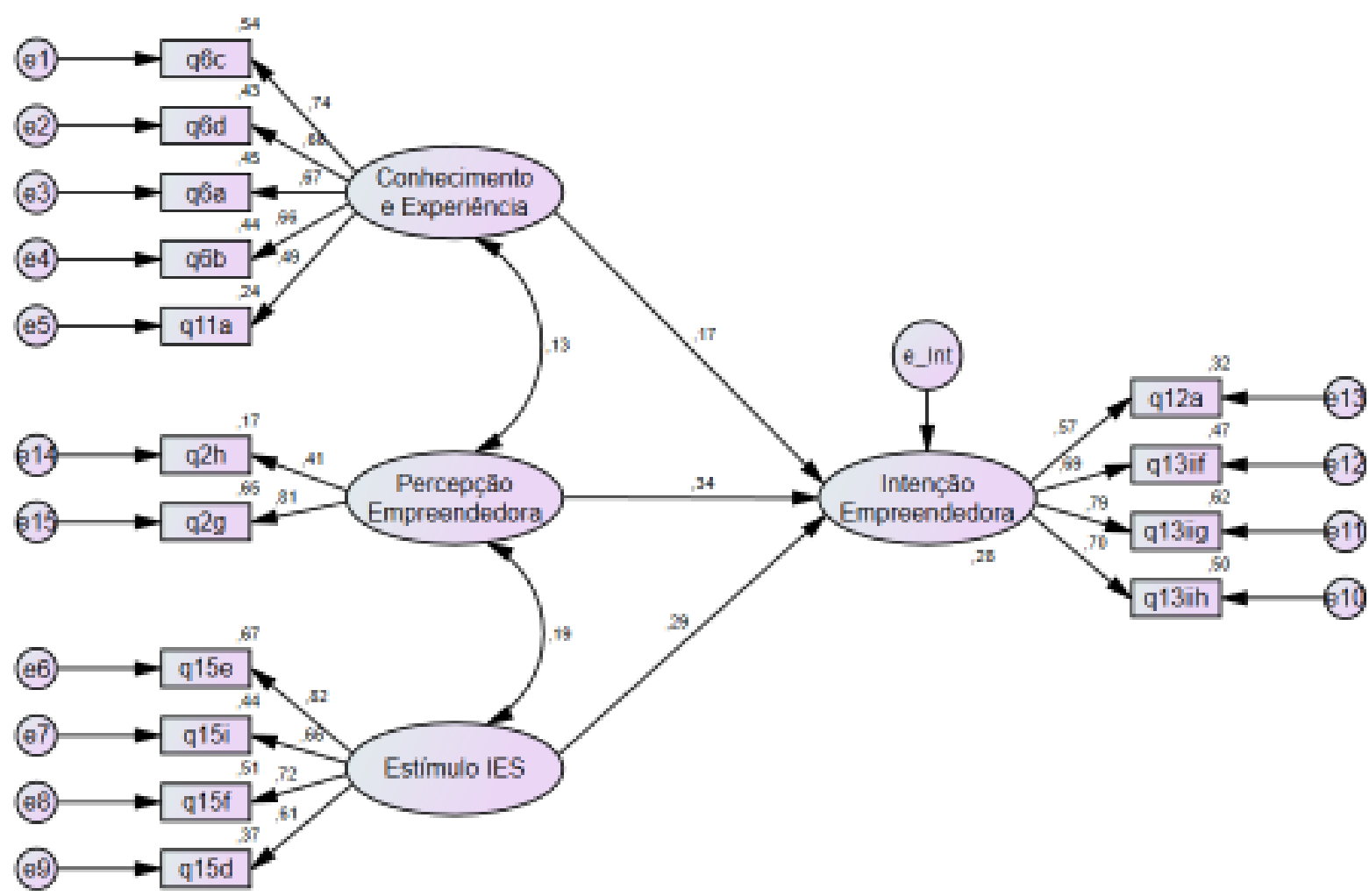

Fonte: Elaborado pelos autores.

A Tabela 6 mostra as estatísticas p-value dos modelos estrutural e de mensuração.

Tabela 6 - Coeficientes de regressão do Modelo 2

\begin{tabular}{|c|c|c|c|c|c|}
\hline \multicolumn{4}{|c|}{ Relações } & \multirow{2}{*}{$\begin{array}{c}\text { Coeficiente } \\
0,167\end{array}$} & \multirow{2}{*}{$\frac{p_{\text {-value }}{ }^{a}}{0,035}$} \\
\hline \multirow{3}{*}{$\begin{array}{l}\text { Modelo } \\
\text { Estrutural }\end{array}$} & Int_Empreend & $\leftarrow$ & Conhec_Exp & & \\
\hline & Int_Empreend & $\leftarrow$ & Estimulo_IES & 0,295 & *** \\
\hline & Int_Empreend & $\leftarrow$ & Percep_Empreend & 0,335 & 0,001 \\
\hline \multirow{15}{*}{$\begin{array}{l}\text { Modelo de } \\
\text { Mensuração }\end{array}$} & $q 6 c$ & $\leftarrow$ & Conhec_Exp & 0,735 & $\mathrm{n} / \mathrm{a}$ \\
\hline & q6d & $\leftarrow$ & Conhec_Exp & 0,655 & $* * *$ \\
\hline & q6a & $\leftarrow$ & Conhec_Exp & 0,673 & $* * *$ \\
\hline & $q 6 b$ & $\leftarrow$ & Conhec_Exp & 0,663 & $* * *$ \\
\hline & q11a & $\leftarrow$ & Conhec_Exp & 0,489 & *** \\
\hline & q15e & $\leftarrow$ & Estimulo_IES & 0,820 & $\mathrm{n} / \mathrm{a}$ \\
\hline & $q 15 i$ & $\leftarrow$ & Estimulo_IES & 0,664 & *** \\
\hline & $q 15 f$ & $\leftarrow$ & Estimulo_IES & 0,716 & $* * *$ \\
\hline & q15d & $\leftarrow$ & Estimulo_IES & 0,610 & $* * *$ \\
\hline & $\mathrm{q} 2 \mathrm{~h}$ & $\leftarrow$ & Percep_Empreend & 0,414 & $\mathrm{n} / \mathrm{a}$ \\
\hline & q2g & & Percep_Empreend & 0,806 & 0,012 \\
\hline & q13iih & $\leftarrow$ & Int_Empreend & 0,704 & $\mathrm{n} / \mathrm{a}$ \\
\hline & q13iig & $\leftarrow$ & Int_Empreend & 0,786 & $* * *$ \\
\hline & q13iif & $\leftarrow$ & Int_Empreend & 0,689 & $* * *$ \\
\hline & q12a & $\leftarrow$ & Int_Empreend & 0,570 & $* * *$ \\
\hline
\end{tabular}

Fonte: Dados da pesquisa;

a quando "n/a", trata-se de coeficiente não padronizado de relações fixadas em "1" para o teste do modelo. 
Vê-se que todos os coeficientes de regressão do modelo de mensuração foram significativos a $1 \%$ ( $p$-value < 0,001), à exceção da variável "q2g", cujo coeficiente se revelou significativo a 5\% ( $p$-value =0,012), e sustentando, diferentemente do modelo 1, a permanência do construto Percepção Empreendedora.

Um terceiro modelo foi testado, agora incluindo uma relação de covariância entre os construtos Conhecimento \& Experiência e Estímulo IES, tendo em vista que os estímulos proporcionados por Instituições de Ensino Superior através de feiras, eventos e conferências sobre empreendedorismo e trocas de experiências (PAÇO et al., 2010; LANERO et al., 2011; SÁNCHEZ, 2011) têm potencial para ampliar o conhecimento e a experiência dos estudantes sobre o tema (TEIXEIRA \& DAVEY, 2010), influenciando sua propensão para empreender. Este modelo está representado na Figura 3.

\section{Figura 3 - Modelo de intenção empreendedora 2}

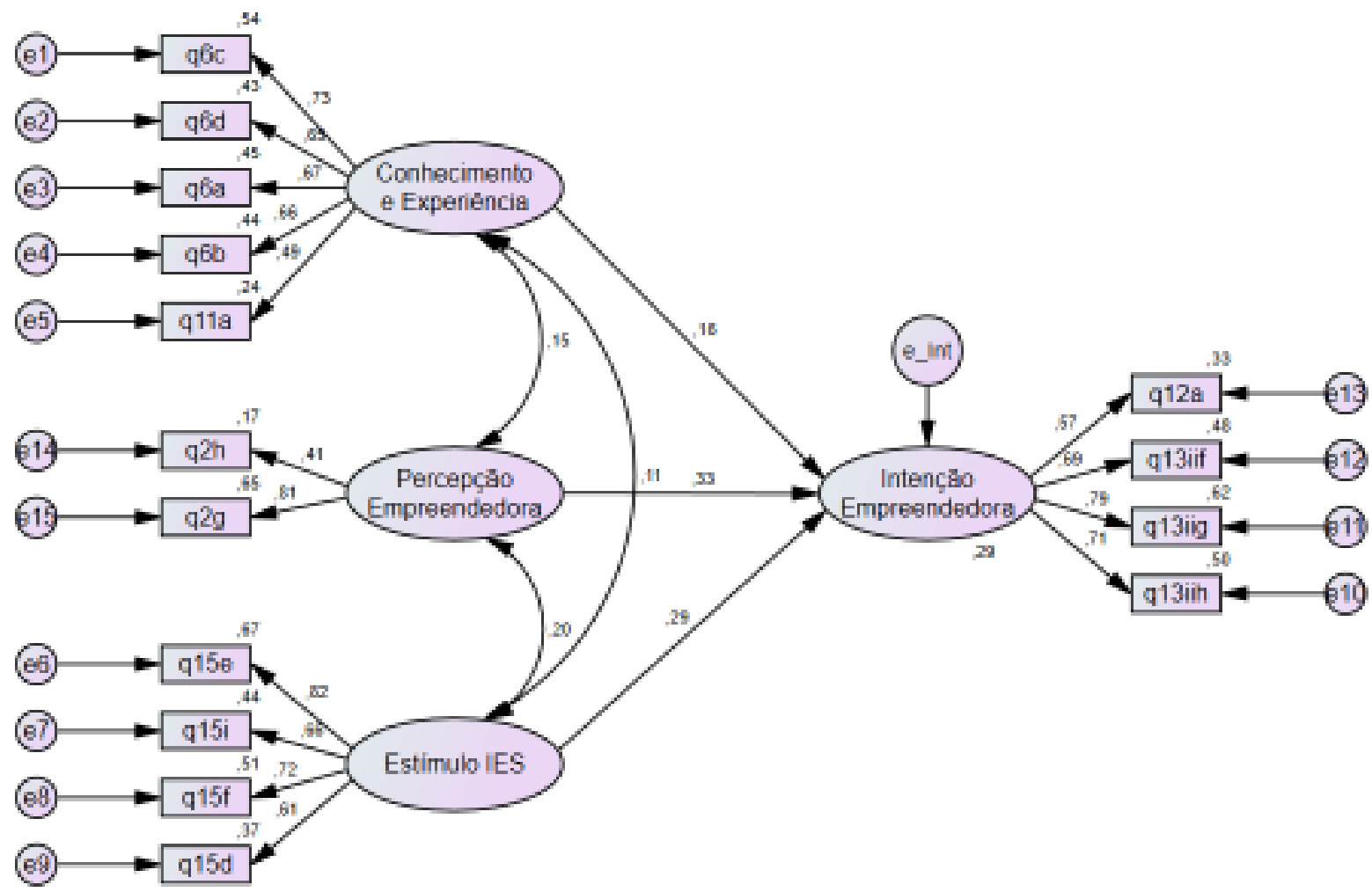

Fonte: Elaborado pelos autores.

Observou-se que a inclusão da covariância entre os construtos Conhecimento \& Experiência e Estímulo IES não trouxe grandes alterações para os valores de cargas fatoriais das relações, em comparação com o modelo 2, anteriormente discutido. O construto Percepção Empreendedora mantém a maior contribuição sobre a Intenção Empreendedora $(0,334 ; p$-value $=0,001)$. Estímulo IES $(0,290 ; p$-value $<0,001)$ apresentou o segundo escore fatorial sobre a Intenção Empreendedora. Finalmente, o construto Conhecimento \& Experiência Empreendedora $(0,160 ; p$-value $=0,043)$. Portanto, os três construtos apresentam influência positiva e significativa sobre a intenção empreendedora dos estudantes da amostra, aos níveis de $1 \%, 1 \%$ e $5 \%$, respectivamente, validando $\mathrm{H}_{1}, \mathrm{H}_{2}$ e $\mathrm{H}_{3}$.

A Tabela 7 resume as estatísticas $p$-value e os coeficientes de regressão padronizados das relações, tanto para o modelo estrutural quanto para o modelo de medida. 
Tabela 7 - Coeficientes de regressão do Modelo 3

\begin{tabular}{|c|c|c|c|c|c|}
\hline \multicolumn{4}{|c|}{ Relações } & Coeficiente & $p$-value ${ }^{a}$ \\
\hline \multirow{3}{*}{$\begin{array}{l}\text { Modelo } \\
\text { Estrutural }\end{array}$} & Int_Empreend & $\leftarrow$ & Conhec_Exp & 0,160 & 0,043 \\
\hline & Int_Empreend & $\leftarrow$ & Estimulo_IES & 0,290 & *** \\
\hline & Int_Empreend & $\leftarrow$ & Percep_Empreend & 0,334 & 0,001 \\
\hline \multirow{15}{*}{$\begin{array}{c}\text { Modelo de } \\
\text { Mensuração }\end{array}$} & $q 6 c$ & $\leftarrow$ & Conhec_Exp & 0,734 & $\mathrm{n} / \mathrm{a}$ \\
\hline & $q 6 d$ & $\leftarrow$ & Conhec_Exp & 0,654 & $* * *$ \\
\hline & q6a & $\leftarrow$ & Conhec_Exp & 0,671 & $* * *$ \\
\hline & $q 6 b$ & $\leftarrow$ & Conhec_Exp & 0,665 & $* * *$ \\
\hline & q11a & $\leftarrow$ & Conhec_Exp & 0,493 & $* * *$ \\
\hline & q15e & $\leftarrow$ & Estimulo_IES & 0,821 & $\mathrm{n} / \mathrm{a}$ \\
\hline & $q 15 i$ & $\leftarrow$ & Estimulo_IES & 0,663 & $* * *$ \\
\hline & $q 15 f$ & $\leftarrow$ & Estimulo_IES & 0,715 & $* * *$ \\
\hline & q15d & $\leftarrow$ & Estimulo_IES & 0,610 & $* * *$ \\
\hline & q2h & $\leftarrow$ & Percep_Empreend & 0,414 & $\mathrm{n} / \mathrm{a}$ \\
\hline & q2g & $\leftarrow$ & Percep_Empreend & 0,806 & 0,011 \\
\hline & q13iih & $\leftarrow$ & Int_Empreend & 0,706 & $\mathrm{n} / \mathrm{a}$ \\
\hline & q13iig & $\leftarrow$ & Int_Empreend & 0,787 & $* * *$ \\
\hline & q13iif & $\leftarrow$ & Int_Empreend & 0,691 & $* * *$ \\
\hline & q12a & $\leftarrow$ & Int_Empreend & 0,572 & $* * *$ \\
\hline
\end{tabular}

Fonte: Dados da pesquisa;

a quando "n/a", trata-se de coeficiente não padronizado de relações fixadas em "1" para o teste do modelo.

Uma análise dos índices de ajustamento absoluto, parcimonioso e incremental para os três modelos propostos e discutidos foi realizada, a fim de identificar qual o modelo mais adequado para explicar o fenômeno da intenção empreendedora entre os jovens estudantes da amostra.

\section{Avaliação de ajustamento dos modelos propostos}

A tabela 8 apresenta os coeficientes de ajustamento absoluto, incremental e parcimonioso para ambos os modelos propostos.

Tabela 8 - Coeficientes de ajustamento

\begin{tabular}{|c|c|c|c|c|c|}
\hline Ajustamento & Coeficiente & Recomendado & Modelo 1 & Modelo 2 & Modelo 3 \\
\hline \multirow{5}{*}{ Absoluto } & $x^{2} / g \mid$ & Entre 1 e 3 & 1,474 & 1,431 & 1,425 \\
\hline & SRMR & Inferior a 0,07 & 0,069 & 0,059 & 0,053 \\
\hline & GFI & Superior a 0,9 & 0,933 & 0,937 & 0,938 \\
\hline & AGFI & Superior a 0,9 & 0,907 & 0,912 & 0,912 \\
\hline & \begin{tabular}{|l} 
RMSEA \\
$(90 \%$ IC $)$ \\
\end{tabular} & Inferior a 0,08 & $\begin{array}{c}0,045 \\
(0,027-0,061)\end{array}$ & $\begin{array}{c}0,043 \\
(0,024-0,059) \\
\end{array}$ & $\begin{array}{c}0,043 \\
(0,023-0,059) \\
\end{array}$ \\
\hline \multirow{2}{*}{ Incremental } & $\mathrm{CFI}$ & Superior a 0,95 & 0,955 & 0,960 & 0,961 \\
\hline & $\mathrm{NFI}$ & Superior a 0,95 & 0,875 & 0,881 & 0,883 \\
\hline \multirow{3}{*}{ Parcimonioso } & PNFI & Superior a 0,5 & 0,725 & 0,713 & 0,706 \\
\hline & PCFI & Superior a 0,5 & 0,791 & 0,777 & 0,769 \\
\hline & PGFI & Superior a 0,5 & 0,676 & 0,664 & 0,657 \\
\hline
\end{tabular}

Fonte: Dados da pesquisa. 
Apesar de as relações de covariâncias entre os construtos exógenos inseridas no modelo 2 ( $p$-values de 0,200 e 0,094 ) e no modelo 3 ( $p$-values de $0,160,0,082$ e 0,166) não terem se mostrado significativas a um nível de $5 \%$, sua inclusão contribuiu para a melhoria do ajustamento em ambas as reespecificações. A partir da tabela 8 , os indicadores de ajustamento sugerem que o modelo 3 é mais adequado.

Vê-se que o índice de ajustamento incremental NFI foi o único que se apresentou fora do limiar considerado aceitável $(>0,95)$. Tal fato pode estar relacionado com o tamanho não tão elevado da amostra da pesquisa, de 236 respondentes (sabe-se que o NFI toma a estatística $X^{2}$ em seu cálculo, e esta, por seu turno, tem estreita relação com tamanho da amostra). Por outro lado, todos os demais indicadores mostraramse adequados, pelo que se considera a solução proposta pelo modelo 3 apropriada para os fins desta pesquisa.

\section{CONSIDERAÇÕES FINAIS}

Tomando-se de partida o modelo com os melhores indicadores de ajustamento, os resultados apresentados permitem chegar a importantes conclusões. Em relação ao modelo de mensuração, e primeiramente detendo-se ao construto Conhecimento \& Experiência Empreendedora, notou-se que as variáveis com os maiores escores fatoriais foram "q6c" e "q6a", respectivamente, a afirmação de conhecimentos para a criação de planos de negócio e conceito de negócio $(0,734)$, e domínio de técnicas para identificar as demandas de mercado $(0,671)$. Estes resultados confirmam os achados por Venesaar, Kallaste e Küttim (2014), e estão em linha com as conclusões de Choi e Park (2015), acerca da importância de prover este tipo de conhecimento técnico ainda no âmbito acadêmico. Um resultado interessante na avaliação deste construto foi percebido no item "q11a", com a menor carga fatorial $(0,493)$. Ou seja, a busca por conhecimentos específicos em empreendedorismo por parte dos respondentes parece não ocorrer de maneira autônoma, o que pode levar a uma ênfase ao papel da universidade neste sentido.

Neste contexto, a análise dos itens de mensuração do construto Estímulo da IES mostrou que o item avaliado com maior carga fatorial pelos estudantes da amostra foi "q15e" ("O meu interesse na criação do meu próprio negócio poderia ser estimulado se a Universidade organizasse conferências/workshops sobre empreendedorismo."), com escore de 0,821 . Em seguida, com escore fatorial de 0,715 , verificou-se o item "q15f" ("O meu interesse na criação do meu próprio negócio poderia ser estimulado se a Universidade aproximasse os alunos das redes de contato necessárias para se começar um negócio."). Isso denota a expectativa dos estudantes em relação ao papel incentivador da instituição de ensino, como evidenciado também por Paço et al. (2011), Lanero et al. (2011), Canever et al. (2013), Venesaar, Kallaste e Küttim (2014) e Rocha e Freitas (2014), para quem as atividades educativas voltadas ao empreendedorismo são determinantes significativos da intenção empreendedora.

Em referência ao construto Percepção Empreendedora, destaca-se a variável "q2g" (com escore fatorial de 0,806 ), que aborda as características percebidas pelos respondentes acerca da figura do empreendedor, como sendo alguém dotado de entusiasmo e persistência, iniciativa e paixão pelo que faz. Tais características, por seu potencial inspirativo (RIOT, 2013) e pelas suas frequentes manifestações associadas a comportamentos narcisistas (FOSTER; MISRA; REIDY, 2009), bem como à autoeficácia, a um 
locus de controle interno e à propensão ao risco (MATHIEU; ST-JEAN, 2013), podem influenciar a intenção empreendedora dos estudantes.

Tais aspectos são confirmados ao serem analisadas as variáveis de medida do construto dependente (Intenção Empreendedora). O item com maior carga fatorial foi "q13iig" ("Preferiria ter meu próprio negócio a ser empregado por conta de outrem, pois tenho a possibilidade de realização pessoal."), com carga de 0,787, corroborando os resultados obtidos por Sagie e Elizur (1999), bem como por Teixeira e Davey (2010). Em seguida, o item "q13iih" ("Preferiria ter meu próprio negócio a ser empregado por conta de outrem, pois é mais prestigiante."), com carga de 0,706 , reforça a visão narcisista percebida pelos estudantes da amostra, em linha com os estudos de Mathieu e St-Jean (2013).

Em vista das discussões anteriores, observa-se que os objetivos propostos no estudo foram alcançados. Modelos estruturais amparados por teorias foram avaliados e testados. Para um deles, o modelo 3, melhor ajustado, foi validada empiricamente sua capacidade explicativa da intenção empreendedora dos estudantes da amostra, pelo que se considera o objetivo principal atendido. Quanto ao objetivo específico, as variáveis adotadas trazem uma nova abordagem para a análise da intenção empreendedora em relação aos aspectos contextuais, complementando a pesquisa mais tradicional no campo, que se vale de direcionadores demográficos ou psicológicos, igualmente importantes.

A confirmação das hipóteses sugeridas, de que os fatores "Conhecimento \& Experiência Empreendedora", "Percepção Empreendedora" e "Estímulo da IES" possuem influência significativa na intenção dos estudantes de empreender, além de validar empiricamente os pressupostos teóricos, amplia o leque de ações que podem ser adotadas nos âmbitos acadêmico, governamental e, ainda, empresarial.

A Percepção Empreendedora, que representa o domínio teórico que os estudantes têm acerca do tema, pode influenciá-los a perseguir esta arriscada - mas entusiasmante - carreira, e suscitar inquietações relacionadas aos interesses sociais envolvidos, para além das preocupações com negócio. Portanto, academia e governos deveriam atuar de modo a promover esta sensibilização. No âmbito empresarial, companhias poderiam fomentar o empreendedorismo interno, seja para obter melhores resultados de seus profissionais com atitudes empreendedoras, seja para a formação e consolidação de spin-offs.

Os resultados igualmente confirmam que a propensão dos estudantes a empreender pode ser incentivada pelas universidades (fator Estímulo IES) por meio da criação de uma atmosfera propícia e estimulante, via projetos de empreendedorismo, eventos e conferências, agregando a participação de empreendedores externos e de alunos que já tenham iniciado o próprio negócio. A academia pode propiciar aproximação com instituições importantes, como bancos, incubadoras e fundos de venture capital ou seed capital.

No que tange ao fator Conhecimento \& Experiência Empreendedora, confirmou-se que a habilidade técnica na lide com as preferências do mercado (exemplo: capacidade de identificar tendências) e a compreensão das etapas de transformação de uma ideia em negócio concreto são indutores da intenção empreendedora. Quanto maior tal habilidade - e ela pode ser incrementada por meio da busca regular de informações, livros e artigos, participação em congressos e feiras - mais propenso estará o estudante a empreender. Da mesma forma, saber como e onde buscar financiamento para a implantação é fundamental. Neste momento, o empreendedor colocará à prova outra competência relevante: a elaboração de planos de 
negócio completos, coerentes e realistas. Há, portanto, oportunidades para a academia e os órgãos de governo atuarem como facilitadores, promovendo políticas neste sentido.

Importantes desafios na construção deste artigo foram impostos pela tentativa de aplicar um questionário que, embora validado, não fora originalmente elaborado para realização de análise fatorial e modelos de equações estruturais. Isso leva a recomendações de novos estudos que possam replicar a abordagem aqui utilizada, de preferência com amostras ainda maiores e mais diversas (por exemplo, abrangendo mais de uma instituição).

Neste sentido, seria oportuno, por exemplo, realizar uma pesquisa abordando estudantes de Administração e Ciências Econômicas matriculados nos semestres finais de seus respectivos cursos; tal estratégia de pesquisa poderia ter valor complementar, ao permitir avaliar a influência da universidade na formação da intenção empreendedora, por meio da comparação dos resultados com aqueles encontrados neste artigo, e que se referem a alunos ingressantes.

Também seria oportuno construir um novo questionário que tenha como objetivo, desde sua gênese, a proposição de modelos de equações estruturais que expliquem a intenção empreendedora de estudantes universitários. Isso pode facilitar deveras o processo de redução fatorial (se for o caso), culminando com a sugestão de modelos alternativos que possam, inclusive, ser comparados a este, aqui proposto.

\section{$\underline{\text { Notas }}$}

1 Embora as variáveis "q11a" e "q12a" tenham apresentado comunalidades ligeiramente inferiores a 0,5, suas medidas de adequação da amostra (MSA) foram superiores a 0,5 na matriz anti-imagem de correlações $(0,791$ e 0,841, respectivamente). Assim, optou-se por não excluí-las (FÁVERO et al., 2009).

2 Idem nota anterior.

${ }^{3}$ Embora o teste de confiabilidade tenha sido baixo para o último fator latente (alpha de Cronbach < 0,6), o mesmo permaneceu no estudo, em virtude de (i) "a utilização de uma única estimativa de fiabilidade como base para concluir sobre um instrumento é sujeita a erro, visto que qualquer estimativa está igualmente sujeita a erro" (MARÔCO; GARCIAMARQUES, 2006, p. 80); (ii) o alpha é uma estimativa lower-bound, ou seja, tem grande probabilidade de ser muito maior do que o valor obtido (CORTINA, 1993 apud TAVAKOL; DENNICK, 2011); (iii) o instrumento de coleta não foi desenvolvido originalmente para aplicação de AFE ou AFC - esforço empreendido neste artigo - e só o repetido uso do instrumento com diferentes amostras poderá confirmar, de fato, sua validade e consistência (MARÔCO; GARCIA-MARQUES, 2006, p. 80); e, concluindo, (iv) todas as demais estimativas ora demonstradas sugerem a manutenção das variáveis no estudo. ${ }^{4}$ Para maiores detalhamentos sobre os índices de ajustamento utilizados, recomenda-se consultar Hair et al. (2009, p. 567-574) e Marôco (2010, p. 40-51). 


\section{REFERÊNCIAS}

AJZEN, I.; FISHBEIN, M. The Prediction of Behavior from Attitudinal and Normative Variables. Journal of Experimental Social Psychology, v. 6, p. 466-487, 1970.

AJZEN, I.; FISHBEIN, M. Understanding Attitudes and Predicting Social Behavior. Englewood Cliffs, NJ: Prentice-Hall, 1980.

AJZEN, I.; MADDEN, T. J. Prediction of goal-directed behavior: Attitudes, intentions, and perceived behavioral control. Journal of Experimental Social Psychology, v. 22, p. 453-474, 1986.

AJZEN, I. The Theory of Planned Behavior. Organizational Behavior and Human Decision Processes, v. 50, p. 179-211, 1991.

AUDET, J. Evaluation of two approaches to entrepreneurship education using an intention-based model of venture creation. Academy of Entrepreneurship Journal, v. 6, n. 1, p. 58-63, 2000.

BARBOSA, S. D.; GERHARDT, M. W.; KICKUL, J. R. The Role of Cognitive Style and Risk Preference on Entrepreneurial Self-Efficacy and Entrepreneurial Intentions. Journal of Leadership and Organizational Studies, v. 13, n. 4, p. 86-104, 2007.

BIRD, B. J. The operation of intentions in time: The emergence of the new venture. Entrepreneurship Theory and Practice, v. 17, n. 1, p. 11-20, 1992.

BOSMA, N.; VAN PRAAG, M.; DE WIT, G. Determinants of Successful Entrepreneurship. Research Report 0002/E. EIM Business and Policy Research, 2000.

BUSENITZ, L. W.; LAU, C.-M. A cross-cultural cognitive model of new venture creation. Entrepreneurship Theory and Practice, v. 20, n. 4, p. 25-40, 1996.

CANEVER, M. D.; KOHLS, V. K.; LAGEMANN, M.; RIGATTO, P. Empreendedorismo: por que alguns estudantes e não outros escolhem ser empreendedores? Estudos e Pesquisas em Psicologia, v. 13, n. 1, p. 101-124, 2013.

CARVALHO, P. M. R.; GONZÁLEZ, L. Modelo explicativo sobre a intenção empreendedora. Comportamento Organizacional e Gestão, v. 12, n. 1, p. 43-65, 2006.

CHOI, M.; PARK, E. The effects of youth education on entrepreneurship. Information, v. 18, n. 5, p. 1983-1990, 2015.

COLLIS, J.; HUSSEY, R. Pesquisa em Administração: um guia prático para alunos de graduação e pós-graduação. 2. ed. Porto Alegre: Bookman, 2005.

DAVIDSSON, P. Determinants of entrepreneurial intentions. Comunicação apresentada na conferência Rent IX, Piacenza, Itália, 23-24 de Novembro, 1995.

DAS, T. K.; TENG, B.-S. Time and Entrepreneurial Risk Behavior. Entrepreneurship Theory and Practice, v. 22, n. 2, p. 69-88, 1997.

DE WIT, G.; VAN WINDEN, F. An M-sector, N-group behavioral model of self-employment. Small Business Economics, v. 3, p. 49-66, 1991.

DELMAR, F.; DAVIDSSON, P. Where do they come from? Prevalence and characteristics of nascent entrepreneurs. Entrepreneurship and Regional Development, v. 12, p. 1-23, 2000.

DOUGLAS, E. J.; SHEPHERD, D. A. Self-employment as a Career Choice: Attitudes, Entrepreneurial Intentions, and Utility Maximization. Entrepreneurial Theory and Practice, v. 26, n. 3, p. 81-90, 2002.

FÁVERO, L. P.; BELFIORE, P.; SILVA, F. L.; CHAN, B. L. Análise de dados: modelagem multivariada para tomada de decisões. Rio de Janeiro: Elsevier, 2009.

FONTENELE, R. E. S. Empreendedorismo, competitividade e crescimento econômico: Evidências empíricas. Revista de Administração Contemporânea, v. 14, n. 6, p. 1094-1112, Nov./Dez. 2010.

FOSTER, J. D.; MISRA, T. A.; REIDY, D. E. Narcissists are approach-oriented toward their money and their friends. Journal of Research in Personality, v. 43, n. 5, p. 764-769, 2009.

FOSTER, J. D.; SHENESEY, J. W.; GOFF, J. S. Why do narcissists take more risks? Testing the roles of perceived risks and benefits of risky behaviors. Personality and Individual Differences, v. 47, n. 8, p. 885-889, 2009.

GARCÍA, A. B. Analyzing the determinants of entrepreneurship in European cities, Small Business Economics, v. 42, p. 77-98, 2014.

GATEWOOD, E. J.; Shaver, K. G.; Powers, J. B.; Gartner, W. B. Entrepreneurial Expectancy, Task Effort, and Performance. Entrepreneurship Theory and Practice, v. 27, n. 2, p. 187-206, 2002.

GÜROL, Y.; ATSAN, N. Entrepreneurial characteristics amongst university students: Some insights for entrepreneurship education and training in Turkey. Education + Training, v. 48, n. 1, p. 25-38, 2006. 
HAIR, J. F.; BLACK, W. C.; BABIN, B. J.; ANDERSON, R. E.; TATHAM, R. L. Análise Multivariada de Dados. Tradução: Adonai Schlup Sant'anna. 6. ed. Porto Alegre: Bookman, 2009.

HISRICH, R. D. Entrepreneurship/Intrapreneurship. American Psychologist, v. 45, n. 2, p. 209-222, 1990.

HYRSKY, K.; TUUNANEN, M. Innovativeness and Risk-taking Propensity: A Cross-Cultural Study of Finnish and U.S. Entrepreneurs and Small Business Owners. The Finnish Journal of Business Economics (LTA), v. 3, p. 238-256, 1999.

LANERO, A.; VÁZQUEZ, J. L.; GUTIÉRREZ, P.; GARCÍA, M. P. The impact of entrepreneurship education in European universities: an intention-based approach analyzed in the Spanish area. International Review on Public and Non-Profit Marketing, v. 8, p. 111-130, 2011.

LIÑÁN, F.; RODRÍGUEZ-COHARD, J. C.; RUEDA-CANTUCHE, J. M. Factors affecting entrepreneurial intention levels: a role for education. International Entrepreneurial Management Journal, v. 7, p. 195-218, 2011.

KRUEGER, N. F. The impact of prior entrepreneurial exposure on perceptions of new venture feasibility and desirability. Entrepreneurship Theory and Practice, v. 18, n. 1, p. 5-21, 1993.

LÜTHJE, C.; FRANKE, N. The "making" of an entrepreneur: testing a model of entrepreneurial intent among engineering students at MIT. R\&D Management, v. 33, n. 2, 2003.

MARÔCO, J. Análise de Equações Estruturais: Fundamentos Teóricos, Software e Aplicações. Pero Pinheiro, Portugal: Report Number, 2010.

MARÔCO, J.; GARCIA-MARQUES, T. Qual a fiabilidade do alfa de Cronbach? Questões antigas e soluções modernas? Laboratório de Psicologia, v. 4, n. 1, p. 65-90, 2006.

MARTÍNEZ, D.; MORA, J.-G.; VILA, L. E. Entrepreneurs, the self-employed and employees amongst young European higher education graduates. European Journal of Education, v. 42, n. 1, p. 92-117, 2007.

MATHIEU, C.; ST-JEAN, É. Entrepreneurial personality: the role of narcissism. Personality and Individual Differences, v. 55, n. 5, p. 527-531, 2013.

NICHOLSON, N. Personality and entrepreneurial leadership: A study of the heads of the UK's most successful independent companies. European Management Journal, v. 16, n. 5, p. 529-539, 1998.

NICKELL, S.; NICOLITSAS, D.; DRYDEN, N. What makes firms perform well? European Economic Review, v. 41, p. 783-796, 1997.

PAÇO, A. M. F.; FERREIRA, J. M.; RAPOSO, M.; RODRIGUES, R. G.; DINIS, A. Behaviours and entrepreneurial intention: Empirical findings about secondary students, Journal of International Entrepreneurship, v. 9, n. 1, p. 20-38, 2011.

PORTER, M. E. A vantagem competitiva das nações. Rio de Janeiro: Campus, 1992.

RIOT, E. Woman in love, artist or entrepreneur?: The edifying, mystifying life of Coco Chanel. Society and Business Review, v. 8, n.3, p. 281-313, 2013.

ROCHA, E. L. C.; FREITAS, A. A. F. Avaliação do ensino de empreendedorismo entre estudantes universitários por meio do perfil empreendedor. Revista de Administração Contemporânea, v. 18, n. 4, p. 465-486, 2014.

ROCK, I. Perception and Knowledge. Acta Psychologica, v. 59, p. 3-22, 1985.

SAGIE, A.; ELIZUR, D. Achievement motive and entrepreneurial orientation: a structural analysis, Journal of Organizational Behavior, v. 20, n. 3, p. 375-87, 1999.

SÁNCHEZ, J. C. University training for entrepreneurial competencies: Its impact on intention of venture creation. International Entrepreneurial Management Journal, v. 7, p. 239-254, 2011.

SHAPERO, A.; SOKOL, L. The Social dimensions of entrepreneurship. In: KENT, C. A.; Sexton, D. L.; Vesper, K. H. (eds.). The Encyclopedia of Entrepreneurship, Englewood Cliffs, NJ: Prentice-Hall, 1982.

SCHMIDT, S.; BOHNENBERGER, M. C. Perfil empreendedor e desempenho organizacional. Revista de Administração Contemporânea, v. 13, n. 3, p. 450-467, Jul./Ago. 2009.

SCHUMPETER, J. A. Capitalismo, socialismo e democracia. Rio: Zahar, 1984.

TAVAKOL, M.; DENNICK, R. Making sense of Cronbach's alpha. International Journal of Medical Education, v. 2, p. 53$55,2011$.

TEIXEIRA, A. A. C. Uma perspectiva internacional das atitudes empreendedoras dos estudantes universitários de economia e gestão. Working Paper, 2013.

TEIXEIRA, A. A. C.; DAVEY, T. Attitudes of Higher Education students to new venture creation: a preliminary approach to the Portuguese case. Industry and Higher Education, v. 24, n. 5, p. 323-341, 2010.

VENESAAR, U.; KALLASTE, M.; KÜTTIM, M. Factors influencing students' venture creation process. Procedia - Social and Behavioral Sciences, v. 110, p. 678-688, 2014. 
VERHEUL, I.; WENNEKERS, S.; AUDRETSCH, D.; THURIK, R. An eclectic theory of entrepreneurship. Discussion Paper TI 2001-030/3, Tinbergen Institute, 2001.

WOOD, M. S.; WILLIAMS, D. W.; GRÉGOIRE, D. A. The Road to Riches? A Model of the Cognitive Processes and Inflection Points Underpinning Entrepreneurial Action. Advances in Entrepreneurship, Firm Emergence and Growth, v. 14, p. 207-252, 2012.

\section{APÊNDICE 1}

\section{Análise Fatorial Exploratória (AFE)}

Após a aplicação do questionário e tabulação dos dados, foi realizada a AFE. Com o intuito de buscar fatores não correlacionados entre si, aumentando a validade discriminante da análise, adotou-se o método de componentes principais para a extração dos fatores, associado ao método de rotação ortogonal Varimax. Buscou-se, assim, reduzir os dados originais para obter o mínimo número de fatores possível com o máximo de variância total explicada (FÁVERO et al., 2009; HAIR et al., 2009).

Após as devidas iterações, eliminaram-se algumas variáveis manifestas que deterioravam a análise de variância, possibilitando uma redução a quatro fatores. Os testes apresentados a seguir apresentam as características de adequação da AFE realizada, iniciando pelos critérios de adequação da amostra (KMO) e confirmação da existência de correlação entre as variáveis manifestas (esfericidade de Bartlett), conforme ilustra a Tabela 1.

Tabela 1 - Medida de KMO e Teste de esfericidade

\begin{tabular}{l|c}
\hline Medida Kaiser-Meyer-Olkin de adequação de amostragem & 0,777 \\
\hline Teste de esfericidade de Bartlett & \\
Qui-quadrado aprox. & 996,439 \\
Df & 105 \\
Sig. & 0,000 \\
\hline
\end{tabular}

Fonte: Dados da pesquisa.

O critério de adequação da amostra encontra-se em um nível considerado médio (KMO entre 0,7 e 0,8), o que viabiliza a aplicação do modelo (FÁVERO et al. 2009). A hipótese nula do teste de esfericidade de Bartlett - de que a matriz de correlação entre as variáveis originais analisadas é uma matriz identidade - foi rejeitada ( $p$-value $<0,000$ ), confirmando correlação entre tais variáveis e dando subsídios para a consecução de uma AFE. Outra medida de adequação da análise é a variância total explicada: 
Tabela 2 - Variância explicada (total e por fator, antes e após a rotação)

\begin{tabular}{|c|c|c|c|c|c|c|}
\hline \multirow[b]{2}{*}{ Componente } & \multicolumn{3}{|c|}{ Autovalores iniciais } & \multicolumn{3}{|c|}{ Solução rotacionada } \\
\hline & Total & $\begin{array}{c}\text { \% de } \\
\text { variância }\end{array}$ & $\%$ cumulativa & Total & $\begin{array}{c}\% \text { de } \\
\text { variância }\end{array}$ & $\begin{array}{c}\% \\
\text { cumulativa }\end{array}$ \\
\hline 1 & 3,710 & 24,731 & 24,731 & 2,685 & 17,897 & 17,897 \\
\hline 2 & 2,392 & 15,945 & 40,676 & 2,511 & 16,743 & 34,640 \\
\hline 3 & 1,766 & 11,776 & 52,452 & 2,487 & 16,580 & 51,220 \\
\hline 4 & 1,217 & 8,111 & 60,563 & 1,401 & 9,343 & 60,563 \\
\hline 5 & ,809 & 5,395 & 65,957 & & & \\
\hline 6 &, 756 & 5,038 & 70,995 & & & \\
\hline 7 & ,665 & 4,432 & 75,428 & & & \\
\hline 8 & ,608 & 4,050 & 79,478 & & & \\
\hline 9 &, 585 & 3,899 & 83,376 & & & \\
\hline 10 &, 523 & 3,488 & 86,865 & & & \\
\hline 11 &, 502 & 3,344 & 90,208 & & & \\
\hline 12 & ,412 & 2,746 & 92,955 & & & \\
\hline 13 & ,383 & 2,555 & 95,510 & & & \\
\hline 14 & ,346 & 2,308 & 97,818 & & & \\
\hline 15 & ,327 & 2,182 & 100,000 & & & \\
\hline
\end{tabular}

Fonte: Dados da pesquisa.

A variância total mínima explicada pelo modelo deve ser maior ou igual a $60 \%$ para que se dê prosseguimento à análise fatorial. Observa-se, conforme Tabela 2, que a redução aos quatro componentes atende a este pré-requisito (> 60,5\%).

Uma investigação sobre as comunalidades é essencial para avaliar a variância explicada pelos fatores latentes em cada variável manifesta. Note-se, pela Tabela 3, que as comunalidades extraídas foram superiores a 0,5 (os fatores latentes explicam mais de $50 \%$ da variância de cada variável observada, ou seja, explicam mais que a variância de erro). 
Tabela 3 - Descrição das variáveis e suas comunalidades extraídas

\begin{tabular}{|c|c|c|}
\hline Variáveis & Descrição & Comunalidades \\
\hline $\mathrm{q} 2 \mathrm{~g}$ & Um empreendedor é alguém que... Tem paixão, entusiasmo, iniciativa e persistência. & 0,643 \\
\hline $\mathrm{q} 2 \mathrm{~h}$ & $\begin{array}{l}\text { Um empreendedor é alguém que... Considera os interesses da sociedade na sua } \\
\text { tomada de decisão. }\end{array}$ & 0,664 \\
\hline q6a & Conheço técnicas para identificar o que o mercado quer. & 0,580 \\
\hline$q 6 b$ & $\begin{array}{l}\text { Compreendo o tipo de questões que se colocam a um empreendedor no momento de } \\
\text { levar uma ideia para o mercado. }\end{array}$ & 0,559 \\
\hline q6c & Consigo criar um plano de negócios e um conceito de negócio. & 0,629 \\
\hline q6d & Sei como financiar legalmente um novo conceito de negócio. & 0,590 \\
\hline $\mathrm{q} 11 \mathrm{a}^{1}$ & Leio regularmente livros/artigos sobre empreendedorismo e inovação. & 0,421 \\
\hline $\mathrm{q} 12 \mathrm{a}^{2}$ & $\begin{array}{l}\text { Durante os seus estudos, quão interessado se revela sobre... Criar um novo negócio a } \\
\text { partir de uma ideia. }\end{array}$ & 0,457 \\
\hline q13iif & $\begin{array}{l}\text { Preferiria ter meu próprio negócio a ser empregado por conta de outrem... Pois é um } \\
\text { trabalho mais interessante. }\end{array}$ & 0,641 \\
\hline q13iig & $\begin{array}{l}\text { Preferiria ter meu próprio negócio a ser empregado por conta de outrem... Pois tenho a } \\
\text { possibilidade de realização pessoal. }\end{array}$ & 0,690 \\
\hline q13iih & $\begin{array}{l}\text { Preferiria ter meu próprio negócio a ser empregado por conta de outrem... Pois é mais } \\
\text { prestigiante. }\end{array}$ & 0,683 \\
\hline$q 15 d$ & $\begin{array}{l}\text { O meu interesse na criação do meu próprio negócio poderia ser estimulado se a } \\
\text { Universidade... Disponibilizasse projetos de trabalho em empreendedorismo. }\end{array}$ & 0,565 \\
\hline q15e & $\begin{array}{l}\text { O meu interesse na criação do meu próprio negócio poderia ser estimulado se a } \\
\text { Universidade... Organizasse conferências/workshops sobre empreendedorismo. }\end{array}$ & 0,710 \\
\hline$q 15 f$ & $\begin{array}{l}\text { O meu interesse na criação do meu próprio negócio poderia ser estimulado se a } \\
\text { Universidade... Aproximasse os alunos das redes de contato necessárias para se } \\
\text { começar um negócio. }\end{array}$ & 0,645 \\
\hline$q 15 i$ & $\begin{array}{l}\text { O meu interesse na criação do meu próprio negócio poderia ser estimulado se a } \\
\text { Universidade... Colocasse os alunos empreendedores em contato uns com os outros. }\end{array}$ & 0,607 \\
\hline
\end{tabular}

Fonte: Dados da pesquisa.

A Tabela 4 apresenta a matriz de componentes rotacionada, com as cargas fatoriais de cada variável em relação ao respectivo componente ou fator. Observe-se que, em cada fator, nenhuma carga menor que 0,5 é verificada, e praticamente todas são maiores que 0,7 , conferindo validade convergente ao modelo. Cargas cruzadas (entre fatores) com coeficientes maiores ou iguais a 0,3 também não são observadas, favorecendo a validade discriminante. A média das cargas de cada variável manifesta dentro do seu respectivo fator latente é sempre significativa e maior que 0,70 , confirmando o poder explicativo da análise, visto que para o tamanho da amostra $(n=236)$, poderiam ser consideradas significantes cargas a partir de aproximadamente 0,35 (HAIR et al., 2009). 
Tabela 4 - Matriz rotacionada, coeficiente de confiabilidade e construtos latentes

\begin{tabular}{|c|c|c|c|c|c|c|}
\hline \multirow{2}{*}{ Variáveis } & \multicolumn{4}{|c|}{ Componente $^{\mathrm{a}}$} & \multirow{2}{*}{$\begin{array}{c}\text { Alfa de } \\
\text { Cronbach }\end{array}$} & \multirow{2}{*}{ Construto Latente } \\
\hline & 1 & 2 & 3 & 4 & & \\
\hline q6c & 0,792 & & & & \multirow{5}{*}{0,778} & \multirow{5}{*}{ Conhecimento \& Experiência } \\
\hline$q 6 d$ & 0,761 & & & & & \\
\hline q6a & 0,741 & & & & & \\
\hline q6b & 0,719 & & & & & \\
\hline q11a & 0,594 & & & & & \\
\hline q15e & & 0,817 & & & \multirow{4}{*}{0,795} & \multirow{4}{*}{ Estímulo IES } \\
\hline$q 15 i$ & & 0,778 & & & & \\
\hline$q 15 f$ & & 0,775 & & & & \\
\hline$q 15 d$ & & 0,727 & & & & \\
\hline q13iih & & & 0,824 & & \multirow{4}{*}{0,781} & \multirow{4}{*}{ Intenção Empreendedora } \\
\hline q13iig & & & 0,802 & & & \\
\hline q13iif & & & 0,787 & & & \\
\hline $\mathrm{q} 12 \mathrm{a}$ & & & 0,593 & & & \\
\hline$q 2 h$ & & & & 0,806 & \multirow{2}{*}{$0,501^{3}$} & \multirow{2}{*}{ Percepção Empreendedora } \\
\hline q2g & & & & 0,759 & & \\
\hline
\end{tabular}

A Tabela 4 também exibe os coeficientes Alfa de Cronbach que medem a confiabilidade da redução. São as informações obtidas a partir da AFE, e de acordo com a teoria abordada na seção 3 deste artigo, essenciais para a construção e teste de modelos estruturais.

O esforço de recorrentes iterações durante a realização da AFE, objetivando respeitar o requisito de suporte teórico bem como os parâmetros mínimos aceitáveis (variância total explicada, qualidade de ajuste da amostra, comunalidades, validades convergente e discriminante), culminou com a eliminação de variáveis e construtos importantes para a explicação da intenção empreendedora, como "propensão ao risco" - a exemplo do que mostram os estudos de Hyrsky e Tuunanen (1999), Barbosa, Gerhardt e Kickul (2007) e Douglas e Shepherd (2002) - e "necessidade de realização" - conforme pesquisas de Sagie e Elizur (1999) e Teixeira e Davey (2010). Por outro lado, novos construtos emergiram e complementaram as teorias tradicionais - que se pautam no locus de controle interno do empreendedor - e incorporaram variáveis externas ao indivíduo. 